\section{The new editor greets you}

\author{
Josef S Smolen
}

It is a great privilege and honour to assume the position of editor of the Annals of the Rheumatic Diseases-The EULAR Journal and I am very grateful to the selection committee consisting of members from both constituencies for granting me this opportunity.

Even bigger is the challenge to take on this position as a successor of Professor Tore Kvien. During the 9 years of his editorship, Professor Kvien has continued the work of the founding Editor after initiation of the collaboration between BMJ and EULAR, Professor Leo van der Putte, and has furthered the impact of The EULAR Journal with prudent and far-sighted editorial decisions. These have allowed the Annals to become the leading journal in the field of rheumatology. While a success like this is impossible without receiving good manuscript and especially an excellent team of associate editors, editorial board members and reviewers, Tore's visions and leadership were instrumental for this development. Thank you very much, Tore!

The accomplishments of the Annals during the 18 years since it became The EULAR Journal are so remarkable that much change of the editorial policy is not needed. But there will be a few. Foremost, the team of associate editors as well as the editorial board and the advisory committee will undergo some modification. Many thanks to everyone who has contributed so importantly during the last years-without this support the journal's success would not have been possible. And a wholehearted welcome to the team that will support the efforts during the next term-the editorial team is the major asset of every journal. It will also be a pleasure to collaborate with the team of the BMJ Publishing Group and the EULAR leadership, who have all had important roles in the development of the journal.

Further, plans for some new sections have been made. One of these sections will be called 'Views on News' and is meant to briefly highlight breakthrough research from outside rheumatology that may be pertinent to advance our field. Another section, 'Heroes and Pillars of Rheumatology', will be devoted to persons or scientific

Correspondence to Professor Josef S Smolen, Department of Rheumatology, Medical University of Vienna, 1090 Wien, Vienna, Austria;

josef.smolen@wienkav.at

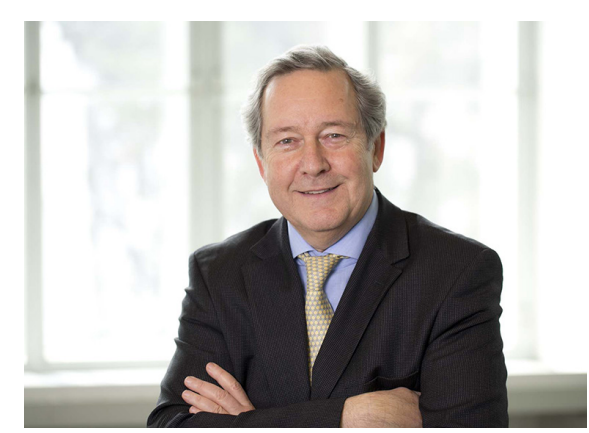

innovations of the past that were pivotal in advancing our discipline-past research tends to be forgotten, younger researchers often do not know enough about the evolution within our specialty and the wheel is often reinvented. This information should not only bring historical aspects into awareness, but also allow to stimulate some novel scientific approaches-much can be learnt from the basics. And thirdly, so that we not only look at the past or at other disciplines, the 'Thinking the Unthinkable' section should solicit and be provided with ideas on accomplishments or developments that may constitute fundamental advancements within our field, but only be realisable within a decade or two-visions, dreams to foster search and most innovative research. I am grateful that Ferdinand Breedveld, Gerd Burmester, Maxime Dougados and David Pisetsky have taken on to lead one or more of these new areas.

Finally, it should be noted that EULAR, alone or in collaboration with $A C R$, has developed a number of recommendations and criteria, such as on reporting data from clinical trials in rheumatoid arthritis. ${ }^{1}$ Not only is adherence to these (and also other) recommendations, as the smallest denominator for clinical trials reports (more can always be added), scientifically important, but it also facilitates future meta-analyses and systematic reviews. The author information will be amended accordingly.

The Annals of the Rheumatic Diseases was founded in 1939 and the joint ownership of the Journal by and collaboration between $B M J$ and EULAR started in 1999; thus, the year 2019 will mark a special dual anniversary which to celebrate appropriately will be one of the objectives of the upcoming editorial term. Appropriate celebration materialises primarily through excellent publications, and it is needless to say that Professor Kvien's path and standards constitute a model to be continued during the next years. It is 'value and interest' of manuscripts related to clinical, epidemiological, basic and translational research that will govern editorial decision making in the future as it in the past.

It can hardly be said better today than stated in 1939 in the first issue of the first volume of the Annals, when Sir William Willcox, the Chairman of the Empire Rheumatism Council at that time, wrote: 'It is intended that the new journal shall consist entirely of original papers and reports, specially selected for their value and interest'. And he ended his foreword by stating: '.... in view of the great activity in so many departments of research into the many manifestations of rheumatic diseases, they may rest assured that they will find no lack of material for the publication ...[in] this valuable journal'.

In this light, it is my desire, hope and expectation that the Annals will continue to attract the best research work of our field. I also look forward to receiving advice and suggestions for further advancement of the journal's quality from all stakeholders, especially the readership of the Annals. Thank you very much in advance for your support!

\section{Competing interests None declared.}

Provenance and peer review Commissioned; internally peer reviewed.

(c) Article author(s) (or their employer(s) unless otherwise stated in the text of the article) 2017. All rights reserved. No commercial use is permitted unless otherwise expressly granted.

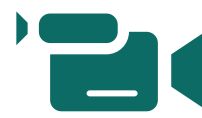

Watch Video

www.goo.gl/e7HUcd

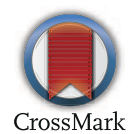

To cite Smolen JS. Ann Rheum Dis 2017:76:1636.

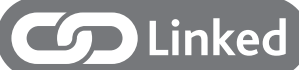

- http://dx.doi.org/10.1136/annrheumdis-2017212235

Ann Rheum Dis 2017;76:1636.

doi:10.1136/annrheumdis-2017-212236

\section{REFERENCES}

1 Aletaha D, Landewe R, Karonitsch T, et al. Reporting disease activity in clinical trials of patients with rheumatoid arthritis: EULAR/ACR collaborative recommendations. Ann Rheum Dis 2008;67:1360-4. 2 Willcox W. Foreword. Ann Rheum Dis 1939;1:1-4. 